Sinha, T. M. Ticich, R. Vander Wal, and F. Crim, Ber. Bunsenges. Phys. Chem. 92, 289 (1988); M. D. Likar, J. E. Baggott, A. Sinha, R. L. Vander Wal, and F. F. Crim, J. Chem. Soc. Faraday Trans. Il 84, 1483 ( 1988); M. D. Likar, J. E. Baggott, and F. F. Crim, J. Chem. Phys. 90, 6266 (1989); A. Sinha, R. L. Vander Wal, and F. F. Crim, J. Chem. Phys. 91, 2929 (1989).

${ }^{7}$ K. Weide, S. Hennig, and R. Schinke, J. Chem. Phys. (in press).

${ }^{8}$ J. F. Cordova, C. T. Rettner, and J. L. Kinsey, J. Chem. Phys. 75, 2742
(1981); S. Zabarnick, J. W. Fleming, and A. P. Baronavski, J. Chem. Phys. 85, 3395 (1986).

${ }^{9}$ The power broadening of the saturated laser induced fluorescence determines the transition linewidths and blends the $Q_{1}(4)$ feature with its satellite $Q_{1}\left(4^{\prime}\right)$.

1"J. Zhang and D. G. Imre (private communication).

'K. Weide and R. Schinke (private communication).

${ }^{12}$ H. Okabe, Photochemistry of Small Molecules (Wiley, New York, 1978).

\title{
Real-time probing of reactions in clusters
}

\author{
J. J. Breen, L. W. Peng, D. M. Willberg, A. Heikal, P. Cong, and A. H. Zewail \\ Arthur Amos Noyes Laboratory of Chemical Physics," California Institute of Technology, Pasadena, \\ California 91125
}

(Received 25 September 1989; accepted 1 November 1989)

In this Communication we report our first study of realtime reaction dynamics in finite size clusters. The reaction is of the type $\mathrm{AH}+\mathrm{S}_{n}$, where the proton transfer (bimolecular) dynamics is examined as the acid $\mathrm{AH}$ is solvated with different number of molecules, $n=1,2, \ldots$ etc. This is in continuation of our effort to study reaction dynamics in real time, ' but now extending the scope of the previous collisionless (solvent free) condition to a range where condensed phase effects can play a role. Of particular interest to us is the condition at which solvation induces vibrational relaxation and modifies IVR. Real-time studies of reactions in clusters offer great opportunities for obtaining the rates directly ${ }^{2}$ and for examining these solvation processes under controlled conditions in molecular beams. Such stepwise solvation by beam methods has been advanced for a variety of systems spanning small molecules, ${ }^{3}$ large molecules, ${ }^{4}$ hydrogenbonded systems, ${ }^{5}$ and electrons. ${ }^{6}$

Here, we use a new molecular beam machine in combination with two picosecond lasers. As before, ${ }^{1}$ the time resolution is achieved by delaying the pump pulse relative to the probe pulse in a Michelson interferometer arrangement, just before the two pulses enter the molecular beam zone (Fig. 1). The mass selection of the skimmed beam is determined by MPI in a time-of-flight spectrometer. Care was taken to lower the pump laser power to a minimum, and the probe wavelength was chosen to create the ions close to threshold ionization. In addition to these pump-probe experiments, picosecond fluorescence measurements were performed using a time correlated single-photon counting apparatus, ${ }^{7}$ similar to earlier studies of isoquinoline-water clusters. ${ }^{5(b)}$

The system of interest here involves the following proton transfer reaction: $\mathrm{AH}^{*} \cdot \mathrm{S}_{n} \rightarrow\left[\mathrm{A}^{-} \cdots \mathrm{S}_{n} \mathrm{H}^{+}\right] \rightarrow \mathrm{A}^{-}+$ $\mathrm{S}_{n} \mathrm{H}^{+}$, where AH stands for $\alpha$-naphthol and $\mathrm{S}_{n}$ for $n$-ammonia molecules. For this system, we report results only for $n=1,2,3$, and 4 , although the cluster distribution is up to $n=30$.

The real-time study reported here shows a critical dependence for the reaction dynamics on the number of solvent molecules involved in the reaction: For $n=1$ and 2 we observe nanosecond dynamics and no evidence for proton transfer; for $n=3$ and 4 the dynamics take place on the picosecond time scale. Our findings should now be relevant to theoretical studies like those by the group of Robinson, ${ }^{8}$ and complement previous time-integrated studies of gasphase ion chemistry, ${ }^{9}$ photoemission and picosecond studies in fluid media, ${ }^{10}$ and intracluster ion chemistry. ${ }^{11}$

Proton transfer reactions specific to naphthols have been the subject of many studies in solutions ${ }^{8,10}$ and matrices. ${ }^{12}$ In clusters, the thorough spectroscopic work of the Leutwyler group ${ }^{13}$ has provided both the spectral shifts for the different clusters and the spectral changes expected under proton transfer conditions. We have used their spectral assignments of bands in our study. More recently, the dynamics of IVR ${ }^{14}$ has been characterized for $\alpha$-naphthol by Lakshminarayan and Knee. ${ }^{15}$

In our study reported here the bare molecule lifetime is measured to be $60 \pm 2 \mathrm{~ns}$ which is in agreement with earlier measurements. ${ }^{13(\mathrm{~d}), 15}$ The $n=1$ cluster has a lifetime of $38 \pm 1 \mathrm{~ns}$. Two isomers have been reported for the cluster with $n=2^{13(a, b)}$; for the spectrally bluer isomer lifetime we measure $43 \pm 2 \mathrm{~ns}$ while for the spectrally redder isomer a lifetime of $39 \pm 1 \mathrm{~ns}$ is observed. In addition, the emission due to the reacted system, emanating predominantly from clusters with $n \geqslant 4$, was monitored at $435 \mathrm{~nm}$ and found to have a lifetime of $38 \pm 2 \mathrm{~ns}$.

For the clusters $n=3$ and 4 the transients measured in the pump-probe experiments reveal a fast decay component of $100 \pm 30$ ps as well as a long (many nanoseconds) decay component. ${ }^{16}$ The cluster size dependence of the onset of the fast dynamics is depicted in Fig. 2 for the clusters $n=1$ and 3 .

For this reaction, which takes place on an electronically excited potential energy surface, the dynamics are dependent on the solvent stabilization of the proton transfer and is therefore cluster size dependent. In a simple description it involves first the IVR among the modes of $\alpha$-naphthol fol- 


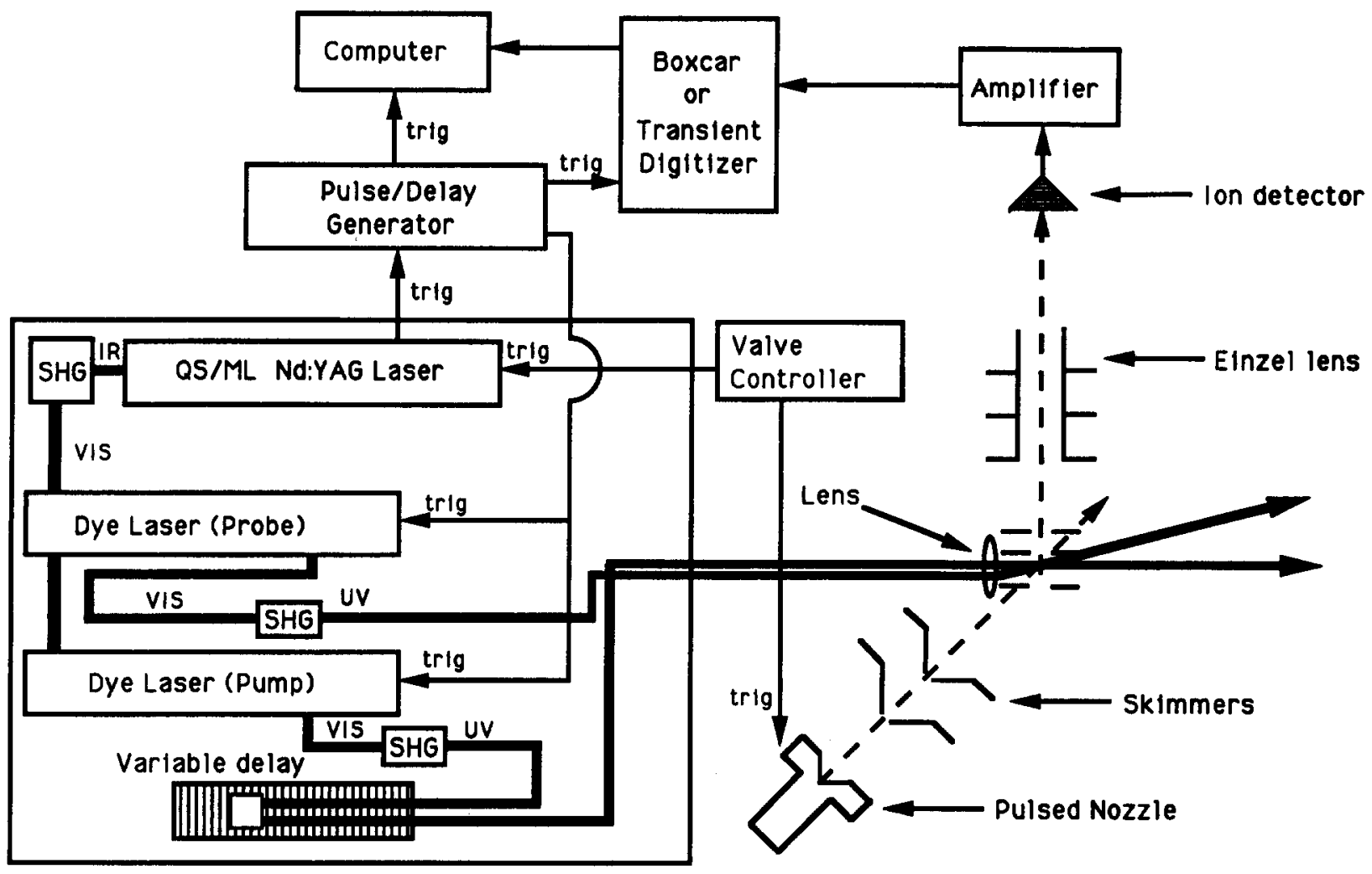

FIG. 1. Schematic of the experimental arrangement depicting the picosecond laser system and cluster beam apparatus.

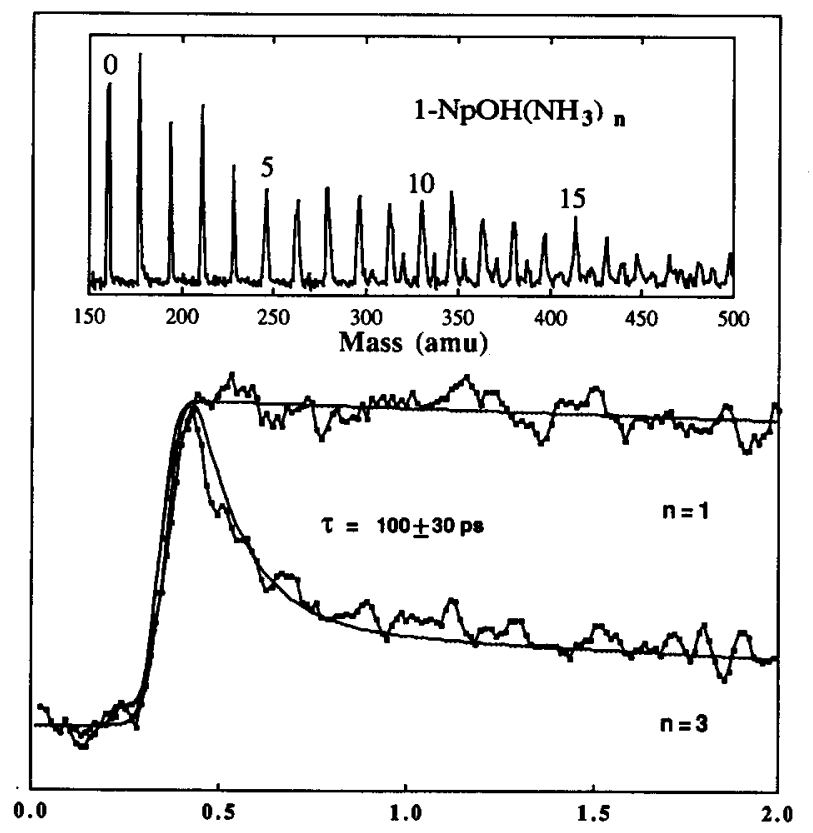

Time (nsec)

FIG. 2. Shown are the decays and fits for the $n=1$ and the $n=3$ clusters. For the $n=1$ cluster, the pump and probe wavelengths are: pump $\lambda=320.4 \mathrm{~nm}$, probe $\lambda=337.1 \mathrm{~nm}$. For the $n=3$ cluster the wavelengths are: pump $\lambda=322.1 \mathrm{~nm}$, and probe $\lambda=337.1 \mathrm{~nm}$. Note that for $n=3$ there is a fast component $(100 \pm 30 \mathrm{ps})$ and a slow component. The insert is a nonresonant photoionization mass spectrum of $\alpha-\mathrm{NpOH}\left(\mathrm{NH}_{3}\right)_{n}$ clusters showing a typical cluster distribution. lowed by the proton transfer to the solvent. The fast $150 \mathrm{ps}$ component is therefore a measure of the IVR/reaction rate taking place in the clusters while the long time component is the lifetime of the equilibrated system. It is interesting that the $100 \mathrm{ps}$ time measured in the cluster is longer than the solution phase reaction time of $33 \pm 5$ ps. ${ }^{10(a)}$

In conclusion, the proton transfer reaction of $\alpha$-naphthol in ammonia clusters is indicative of the size dependent phenomena which time-resolved pump-probe spectroscopy is capable of monitoring directly. More measurements on this system and other cluster systems will be forthcoming. The hope is to characterize IVR and reaction dynamics as $n$ reaches very large numbers.

Note added in proof: Recently, we have studied the clusters of $\alpha$-naphthol with piperidine and water. Fast delay components, similar to that depicted in Fig. 2, were observed for the clusters with piperidine ( $n=2$ or 3 ) but were not observed for the clusters containing water $(n \leqslant 21)$, on the same time scale.

This work is supported by the Air Force Office of Scientific Research and by the National Science Foundation.

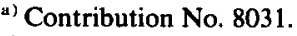

'For recent reviews see: (a) A. H. Zewail, Science 242, 1645 (1988); (b) J. L. Knee and A. H. Zewail, Spectroscopy 5, 44 (1988); (c) A. H. Zewail and R. B. Bernstein, Chem. and Eng. News 66, 24 (1988).

${ }^{2} J$ J. S. Baskin, M. Dantus, and A. H. Zewail, Chem. Phys. Lett. 130, 473 (1986).

${ }^{3}$ (a) D. H. Levy, Adv. Chem. Phys. 47 (Part 1), 323 (1981); (b) R. E. 
Miller, Science 240, 447 (1988).

(a) A. Amirav, U. Even, and J. Jortner, J. Chem. Phys. 74, 3725 (1981); (b) A. Amirav, U. Even, and J. Jortner, J. Chem. Phys. 75, 2489 (1981); (c) A. Amirav, U. Even, and J. Jortner, J. Chem. Phys. 86, 3345 (1986). (a) P. M. Felker, W. R. Lambert, and A. H. Zewail, J. Chem. Phys. 77, 1603 (1982); 78, 5266 (1983); (b) P. M. Felker and A. H. Zewail, Chem. Phys. Lett. 94, 448, 454 (1983); (c) K. Fuke and K. Kaya, Chem. Phys. Lett. 94, 97 (1983); (d) R. Bombach, E. Honegger, and S. Leutwyler, Chem. Phys. Lett. 118, 449 (1985); (e) E. Honegger, R. Bombach, and S. Leutwyler, J. Chem. Phys. 85, 1234 (1986); (f) K. Fuke, H. Yoshiuchi, and K. Kaya, J. Phys. Chem. 88, 5840 (1984); (g) N. P. Ernsting, J. Phys. Chem. 89, 4932 (1985).

'(a) H. Haberland, H. Langush, H. G. Schindler, and D. R. Worsnop, Surf. Sci. 156, 157 (1985); (b) H. Haberland, H. G. Schindler, and D. R. Worsnop, J. Chem. Phys. 81, 3342 (1984); (c) J. V. Coe, J. T. Snodgrass, C. B. Freidhoff, K. M. McHugh, and K. H. Bowen, J. Chem. Phys. 83, 3169 (1985); (d) M. Knapp, O. Echt, D. Kreisle, and E. Recknagle, J. Chem. Phys. 85, 636 (1986); (e) M. Knapp, O. Echt, D. Kreisle, and E. Recknagle, J. Phys. Chem. 88, 270 (1984).

${ }^{7}$ (a) W. R. Lambert, P. M. Felker, and A. H. Zewail, J. Chem. Phys. 81, 2217 (1984); (b) P. M. Felker and A. H. Zewail, J. Chem. Phys. 82, 2975 (1983).

${ }^{8}$ G. W. Robinson, P. J. Thistleethwaite, and J. Lee, J. Phys. Chem. 90, 4224
(1986).

(a) P. Kebarle, Ann. Rev. Phys. Chem. 28, 445 (1977); (b) A. W. Castleman, Jr. and R. G. Keesee, Ann. Rev. Phys. Chem. 37, 525 (1986).

${ }^{10}$ (a) S. P. Webb, L. A. Philips, S. W. Yeh, L. M. Tolbert, and J. H. Clark, J. Phys. Chem. 90, 5154 (1986); (b) E. W. Kosower and D. Huppert, Ann. Rev. Phys. Chem. 37, 127 (1986); (c) D. Huppert, M. Gutman, and K. J. Kaufmann, Adv. Chem. Phys. 47 (Part 2), 323 (1981).

"'(a) J. F. Garvey and R. B. Bernstein, J. Phys. Chem. 90, 3577 (1988); (b) B. Brutschy, C. Janes, and J. Eggert, Ber. Bunsenges. Phys. Chem. 92, 74, 437 (1988).

${ }^{12}$ G. A. Brucker and D. F. Kelley, J. Chem. Phys. 90, 5243 (1989).

${ }^{13}$ (a) O. Cheshnovsky and S. Leutwyler, Chem. Phys. Lett. 121, 1 (1985);

(b) O. Cheshnovsky and S. Leutwyler, J. Chem. Phys. 88, 4127 (1988);

(c) R. Knochenmuss, O. Cheshnovsky, and S. Leutwyler, Chem. Phys. Lett. 144, 317 (1985); (d) R. Knochenmuss and S. Leutwyler, J. Chem. Phys. 91, 1268 (1989).

${ }^{14}$ P. M. Felker and A. H. Zewail, Adv. Chem. Phys. 70, 265 (1988).

${ }^{15} \mathrm{C}$. Lakshminarayan and J. L. Knee, J. Phys. Chem. (in press).

${ }^{16}$ In the pump-probe experiments transients are only recorded over a temporal range of $<4 \mathrm{~ns}$ so it is difficult to accurately measure long lifetimes. For the clusters $n=0,1$, and 2 transients give evidence for long lifetimes, which are consistent with the picosecond fluorescence measurements (see Figure 2).

\title{
Observation of $\mathrm{CH}_{3} \mathrm{Zn}$ as a stable product in the $\mathrm{KrF}$ laser photodissociation of $\left(\mathrm{CH}_{3}\right)_{2} \mathrm{Zn}$
}

\author{
Robert L. Jackson \\ IBM Almaden Research Center, San Jose, California 95120-6099
}

(Received 25 September 1989; accepted 1 November 1989)

Interest in the photophysics and photochemistry of the $\mathrm{Zn}, \mathrm{Cd}$, and $\mathrm{Hg}$ dialkyls has increased recently, due in part to the importance of these molecules in laser photochemical metal deposition processes. ${ }^{1-3}$ Photodissociation of the metal dialkyls occurs extremely rapidly upon excitation to one of the two excited states accessible in the UV. ${ }^{4-6}$ The primary photoproducts are an alkyl radical and the metal monoalkyl. Both are formed in the electronic ground state but with a substantial degree of vibrational excitation. ${ }^{4-9}$ The metal monoalkyl is believed to undergo complete secondary thermal dissociation to the metal atom and a second alkyl radical. ${ }^{4,5}$ This is a reasonable conclusion, since the energy supplied by UV excitation of the metal dialkyls is more than sufficient to break both metal-alkyl bonds and since the second metal-alkyl bond is much weaker than the first. ${ }^{10}$ Strausz and co-workers have shown, however, that $\mathrm{CH}_{3} \mathrm{Zn}$ and $\mathrm{CH}_{3} \mathrm{Cd}$ are spectroscopically observable on a microsecond timescale following photodissociation of $\left(\mathrm{CH}_{3}\right)_{2} \mathrm{Zn}$ and $\left(\mathrm{CH}_{3}\right)_{2} \mathrm{Cd} .{ }^{11}$ While their measurements were not quantitative, Strausz and co-workers found that the intensity of the $\mathrm{CH}_{3} \mathrm{Zn}$ and $\mathrm{CH}_{3} \mathrm{Cd}$ absorption bands increased with increasing buffer gas pressure. This suggests that it may be possible to quench secondary thermal dissociation of the metal monoalkyl. In this paper, we use laser-induced fluorescence (LIF) to measure the relative yields of $\mathrm{Zn}$ and $\mathrm{CH}_{3} \mathrm{Zn}$ quantitatively as a function of $\mathrm{He}$ buffer gas pressure upon $248 \mathrm{~nm}$ photodissociation of $\left(\mathrm{CH}_{3}\right)_{2} \mathrm{Zn}$. We find that
$\mathrm{CH}_{3} \mathrm{Zn}$ is a significant product at low pressure and becomes the major product at modest pressures of He.

Photodissociation of $\left(\mathrm{CH}_{3}\right)_{2} \mathrm{Zn}$ was induced by $\mathrm{KrF}^{*}$ laser $(248 \mathrm{~nm})$ irradiation of the vapor in a gas flow cell constructed from a standard $2 \frac{3{ }^{\prime \prime}}{}$ diameter 6-way cross. ${ }^{12} \mathrm{~A}$ Nd:YAG-pumped dye laser beam, directed collinearly to the $\mathrm{KrF}^{*}$ laser beam, was used to monitor both $\mathrm{CH}_{3} \mathrm{Zn}^{11,13,15}$ and $\mathrm{Zn}^{14,15}$ by laser-induced fluorescence. The delay time between the excimer laser pulse and the dye laser pulse was typically $10-40 \mu \mathrm{s}$. At shorter delay times, the data for $\mathrm{CH}_{3} \mathrm{Zn}$ were complicated by collisional vibrational deactivation processes. At longer delay times, both $\mathrm{Zn}$ and $\mathrm{CH}_{3} \mathrm{Zn}$ begin to diffuse out of the detection zone. Helium was introduced into the cell via ports directed at the laser entrance and exit windows. $\left(\mathrm{CH}_{3}\right)_{2} \mathrm{Zn}$ vapor (Alfa) was introduced through a separate port via a Teflon-lined stainless steel bubbler using $\mathrm{He}$ as a carrier gas. The He buffer gas and $\left(\mathrm{CH}_{3}\right)_{2} \mathrm{Zn} / \mathrm{He}$ flow rates were controlled by separate mass flow controllers, allowing the buffer gas partial pressure to be set independently of the $\left(\mathrm{CH}_{3}\right)_{2} \mathrm{Zn}$ partial pressure ( $\sim 0.1$ Torr).

Upon photodissociation of $\left(\mathrm{CH}_{3}\right)_{2} \mathrm{Zn}$, LIF signals due to $\mathrm{Zn}$ and $\mathrm{CH}_{3} \mathrm{Zn}$ are readily observed at all buffer gas pressures. At a given pressure, the $\mathrm{CH}_{3} \mathrm{Zn}$ and $\mathrm{Zn}$ LIF intensities increase linearly with excimer laser fluence, indicating that each product is formed via single-photon dissociation of $\left(\mathrm{CH}_{3}\right)_{2} \mathrm{Zn}$. Fluorescence from $\mathrm{Zn}$ and $\mathrm{CH}_{3} \mathrm{Zn}$ is not 